\title{
Economical Method of Reducing vibration on Machine Foundation
}

\author{
Ataulla Attar ${ }^{1}$, Dr P G Rakaraddi ${ }^{2}$ \\ ${ }^{1} P$ G student BECBagalkot \\ ${ }^{2}$ professor BEC Bagalkot
}

\begin{abstract}
In this research the effect of different isolated materials between the machine base and its concrete footing block is examined experimentally. The machine is subjected to vertical vibration produce by vibration exitor 4808 oscillator. Experiments will be performed by inserting isolated material between the machine base and its concrete footing. It is examined that the most vibration absorber is sandwich of $E P E$ foam with rubber pad in between the oscillator and block. even on the ground the resonance is reduced so in this research it is investigated that for any kind of machine, combination of $E P$ E foam and rubber pad can be used to reduce the vibration for the foundation and even to reduce damage to the nearby structures and this study will be beneficial for assessing the performance of the machine foundations.
\end{abstract}

Keywords: isolated materials, machine foundations, EPE foam, rubber pad, amplitudes, frequency.

\section{Introduction}

The design of the machine foundation plays an important role in industrial structures. If a machine is rigidly bolted to the floor, the vibratory movement of the machine itself may be reduced, but the vibration transmitted to the floor will be large ${ }^{1}$. This may produce harmful effects even at large distances . The vibration movement of the machine get reduced when the machine is rigidly bolted to the floor, but the vibration transmitted to the floor will increase. Some compromise has, therefore, to be reached between the two requirements. This is achieved in design practice by selecting a suitable natural frequency for the machine foundation. For machines running at a steady speed the degree of isolation is determined by the ratio defined as the ratio of the operating frequency of the machine fz to the natural ${ }^{2}$. The occurrence of resonance and the consequent effect on increase of vibration amplitudes is one of the most common sources of trouble in machine foundations. The possible methods of vibration isolation in existing machine foundations are; Counter-balancing the exciting loads, stabilization of soils, use of structural measures, isolation by The 14th World Conference on Earthquake Engineering October 12-17, 2008, Beijing, China trench barriers ${ }^{3}$, isolation in buildings. The choice of structural measures depends on the nature of vibration and the ratio of natural frequency to the operating frequency. Following are the possible structural measures that can be adopted in appropriate cases; increasing base area or mass of foundation, use of slabs attached to foundation, use of auxiliary spring-mass systems (Demir,1992) ${ }^{4}$.

The disturbance of vibrations to near structures or equipment is understood during design, absorbers must be used in the design to avoid harmful effect of vibrations. If there is a situation where absorbers are inadequate to obtain desired amplitudes, the method of vibration isolation by trench barriers is used. Providing a barrier in the vicinity of the source is defined as active isolation and a barrier remote from vibration source to protect a structure or equipment is defined as passive isolation ${ }^{5}$.

In the present work the amplitude of vibration of the floor is reduced by introducing the E P E foam (Expanded polyethylene) and rubber pad in between the machine and foundation

\subsection{Common Vibration Absorbers}

Commonly used vibration absorbers are; steel or metal springs, cork pads, rubber pads, timber pads, neoprene pads and pneumatic absorbers by choosing a suitable natural frequency, therefore, it is possible to obtain the required degree of Isolation which obviously depends on the ${ }^{7}$

1. Environmental conditions at site.

2. Chemical soil stabilization.

3. Structural measures.

4. Providing vibration dampers.

\section{Objectives}

$>$ Effect of different isolated materials on Dynamic Response of Machine Foundation.

$>$ Relation between frequency and amplitude.

$>$ Study on minimizing the vibration levels and amplitudes. 


\section{Methodology}

Different series of vibrations tests were conducted on a concrete block of size $0.75 \mathrm{~m} * 0.75 * 1 \mathrm{~m}$ near the Geo tech lab of Indian Institute of Technology Mumbai to study the vibration of the floor. The electro dynamic oscillator was used to generate the vibrations. The geophones were placed on the concrete block as well as on the floor. Geophone placed on the floor is at a distance of $0.50 \mathrm{~m}$ from the corner of the block along the side of the block to pick up the vibrations caused by the oscillator. . Series of tests conducted were named as Series A, Series B, Series C, Series D, and Series E. . In Series A, no vibration control material is used (without isolation ), whereas in Series B, C, D and E, a rubber pad of thickness $6 \mathrm{~mm}$, EPE foam of thickness $50.8 \mathrm{~mm}$, foam placed over rubber pad of the same thickness and rubber pad placed over foam is introduced between oscillator and concrete block respectively. Frequency of the oscillator is varied the controller and the corresponding amplititude at the floor and on the concrete block were recorded.. The resonant frequency was gained in all the series of tests. The at most care is taken while conducting the tests to avoid the disturbances caused near the block by other source. The experimental setup is shown in fig....... and E, a rubber pad of thickness $6 \mathrm{~mm}$, EPE foam of thickness $50.8 \mathrm{~mm}$, foam placed over rubber pad of the same thickness and rubber pad placed over foam is introduced between oscillator and concrete block respectively. Frequency of the oscillator is varied by the controller and the corresponding amplitude at the floor and on the concrete block were recorded.. The resonant frequency was gained in all the series of tests. The at most care is taken while conducting the tests to avoid the disturbances caused near the block by other source. The experimental setup is shown in fig......

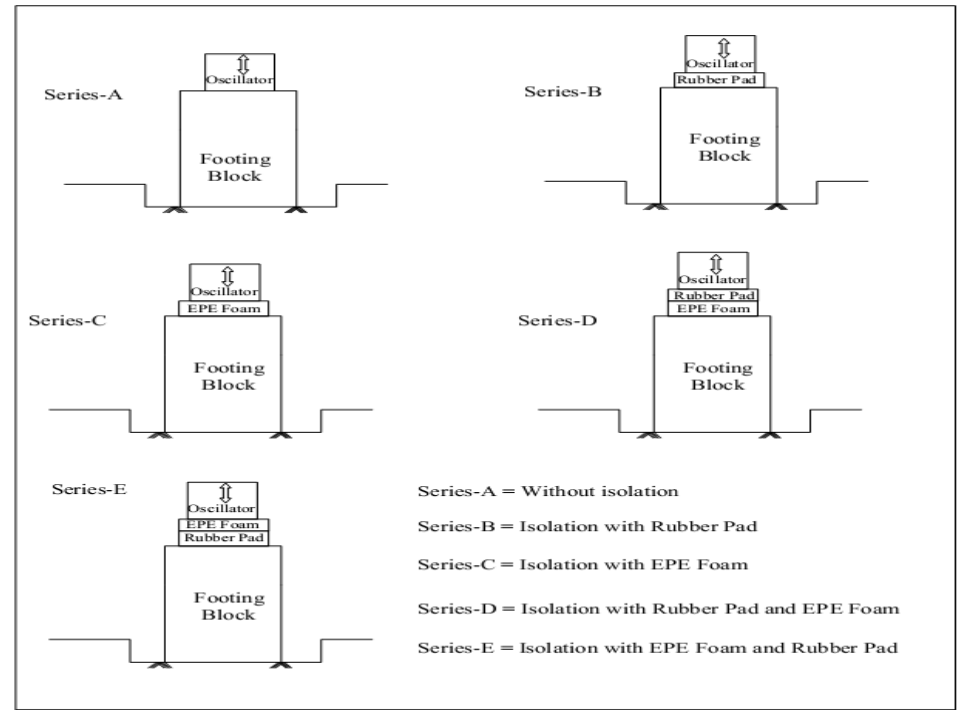

\subsection{Geo Phone on the Block}

Amplitude on block was recorded with the series of A, B, C, D and E and both the parameters frequency and amplitude were recorded

\subsection{Series A without Isolation Materials.}

In series A the geo phone were placed on the block and readings were recorded.

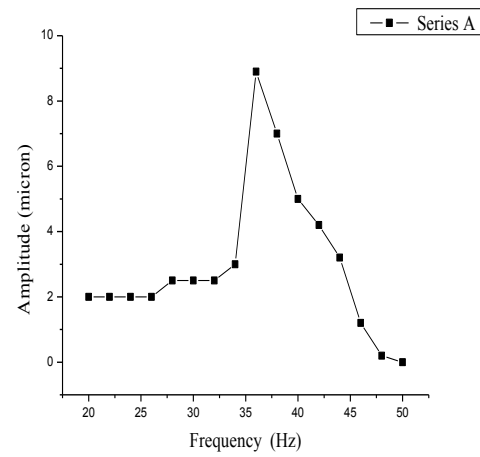

Figure 3.1: Variation of frequency to the amplitude for the test series A 
In series (without isolation) it has been observed that at frequency $36 \mathrm{~Hz}$ the resonance amplitude was gained peak with 8.9 microns which has been observed to be the highest in all the series conducted series $\mathrm{B}, \mathrm{C}, \mathrm{D}, \mathrm{E}$. It can be observed in figure 3.1

\subsection{Series B with Rubber Pad as Isolation Materials}

In series B the geo phone were placed on the block and the rubber pad was placed in between the oscillator and the block readings were recorded as shown in the figure (5.3)

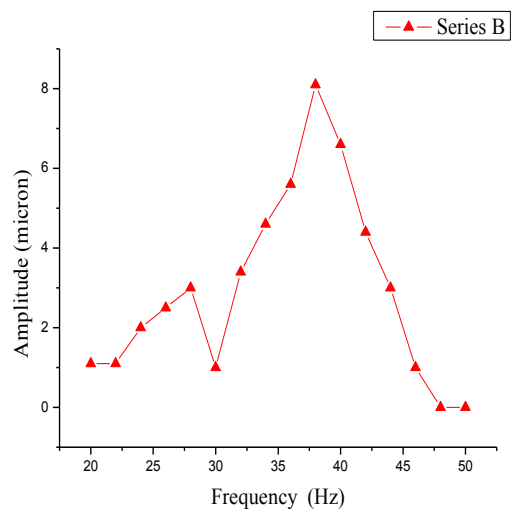

Figure 3.2: Variation of frequency to the amplitude for the test series B

In series B (rubber pad) it has been observed that at frequency $38 \mathrm{~Hz}$ the resonance amplitude was gained peak with 8.1microns which has been observed to be less than series A but more than series C, D and E. It can be observed in figure 3.2 .

\subsection{Series C with E P E foam as Isolation Materials}

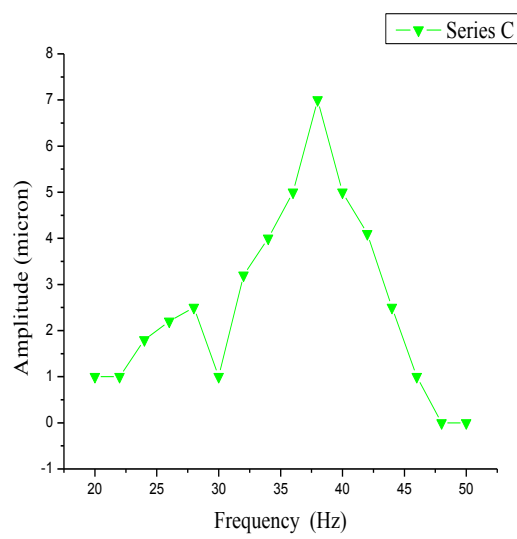

Figure 3.3: Variation of frequency to the amplitude for the test series $\mathbf{C}$

In series C (E P E foam) it has been observed that at frequency $38 \mathrm{~Hz}$ the resonance amplitude was gained peak with 7.0 microns which has been observed to be less than series B but more than series , $\mathrm{d}$,e. It can be observed in figure 3.3 


\subsection{Series D Sandwich of Rubber Pad with E P E foam as Isolation Materials}

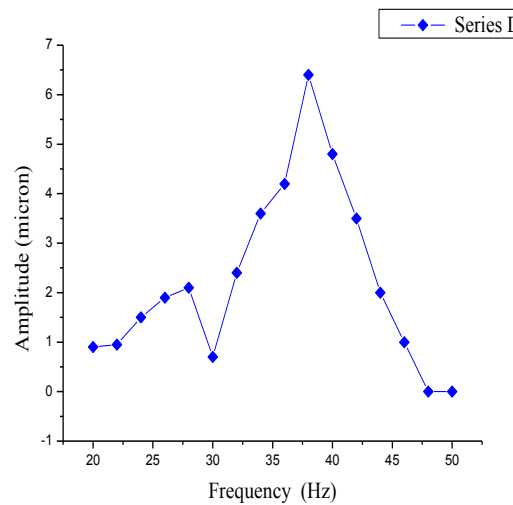

Figure 3.4: Variation of frequency to the amplitude for the test series D

In series D (rubber pad and E P E foam sandwich) it has been observed that at frequency $38 \mathrm{~Hz}$ the resonance amplitude was gained peak with 6.4 microns which has been observed to be less than series $\mathrm{C}$ but more than series E. It can be observed in figure 3.4

\subsection{Series E Sandwich of E P E foam with Rubber Pad as Isolation Materials}

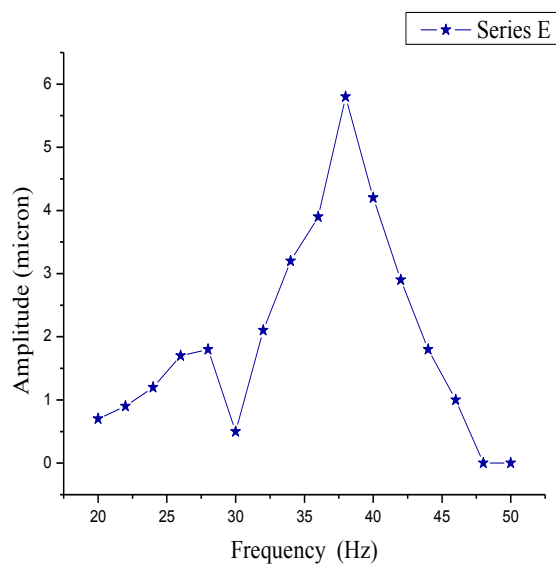

Figure 3.5: Variation of frequency to the amplitude for the test for series $E$

In series E (sandwich of E P E foam and rubber pad) it has been observed that at frequency $38 \mathrm{~Hz}$ the resonance amplitude was gained peak with 5.8 microns which has been observed to be less than all the series conducted above series A,B,C,D. Thus it can be concluded that the most vibration absorber is the series e with sandwich of E P E foam and rubber pad in between the oscillator and block.

\subsection{Comparison of Frequency and Amplitude}

After the comparison with all the series it was observed that the isolation material in between the oscillator and the block behaved in reducing the peak resonance of about $45 \%$. It can be seen that the most vibration absorber is the series $\mathrm{E}$ with sandwich of $\mathrm{E} P \mathrm{E}$ foam with rubber pad in between the oscillator and block. It can be concluded that from comparison with all the series for any kind of machine combination of $\mathrm{E} P$ E foam and rubber pad can be used to reduce the vibration for the foundation and even to reduce damage to the nearby structures. 


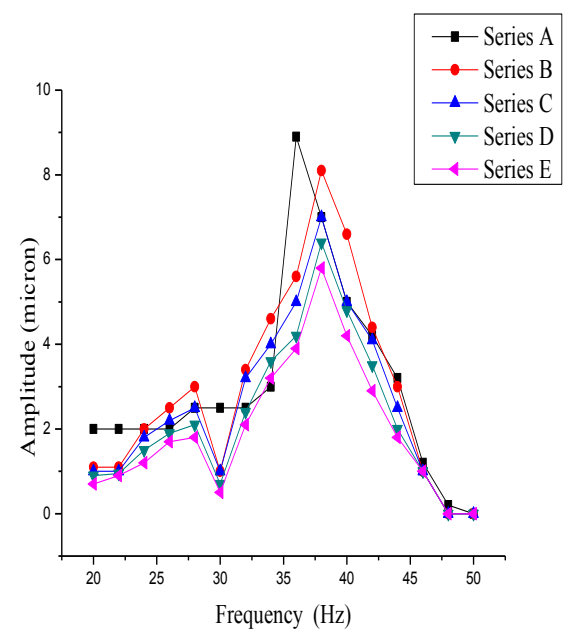

Figure 3.6: Variation of frequency to the amplitude for the test series A, B, C, D and E

Table 3.1: Comparison of Frequency and Amplitude readings taken on block for series A, B, C, D and E

\begin{tabular}{|c|c|c|c|c|c|}
\hline \multirow{2}{*}{$\begin{array}{c}\text { Freque } \\
\text { ncy } \\
(\text { Hz) }\end{array}$} & $\begin{array}{c}\text { Without } \\
\text { Isolation } \\
\text { (Series A) }\end{array}$ & $\begin{array}{c}\text { Rubber } \\
\text { Pad } \\
\text { (Series B) }\end{array}$ & $\begin{array}{c}\text { Foam } \\
\text { (Series } \\
\text { C) }\end{array}$ & $\begin{array}{c}\text { Rubber } \\
\text { Pad } \\
\text { Foam } \\
\text { (Series } \\
\text { D) }\end{array}$ & $\begin{array}{c}\text { Foam } \\
\text { Rubber } \\
\text { Pad } \\
\text { (Series } \\
\text { E) }\end{array}$ \\
\hline 20 & 2 & 1.1 & 1 & 0.9 & 0.7 \\
\hline 22 & 2 & 1.1 & 1 & 0.95 & 0.9 \\
\hline 24 & 2 & 2 & 1.8 & 1.5 & 1.2 \\
\hline 26 & 2 & 2.5 & 2.2 & 1.9 & 1.7 \\
\hline 28 & 2.5 & 3 & 2.5 & 2.1 & 1.8 \\
\hline 30 & 2.5 & 1 & 1 & 0.7 & 0.5 \\
\hline 32 & 2.5 & 3.4 & 3.2 & 2.4 & 2.1 \\
\hline 34 & 3 & 4.6 & 4 & 3.6 & 3.2 \\
\hline 36 & 8.9 & 5.6 & 5 & 4.2 & 3.9 \\
\hline 38 & 7 & 8.1 & 7 & 6.4 & 5.8 \\
\hline 40 & 5 & 6.6 & 5 & 4.8 & 4.2 \\
\hline 42 & 4.2 & 4.4 & 4.1 & 3.5 & 2.9 \\
\hline 44 & 3.2 & 3 & 2.5 & 2 & 1.8 \\
\hline 46 & 1.2 & 1 & 1 & 1 & 1 \\
\hline 48 & 0.2 & 0 & 0 & 0 & 0 \\
\hline 50 & 0 & 0 & 0 & 0 & 0 \\
\hline & & & & & \\
\hline
\end{tabular}

Table 3.2:: Resonant amplitude gained to the frequency for test series A, B, C, D and E

\begin{tabular}{|c|c|c|}
\hline Test & Frequency $(\mathrm{Hz})$ & $\begin{array}{c}\text { Amplitude } \\
\text { (microns) }\end{array}$ \\
\hline Series A & 36 & 8.9 \\
\hline Series B & 38 & 8.1 \\
\hline Series C & 38 & 7 \\
\hline Series D & 38 & 6.4 \\
\hline Series E & 38 & 5.8 \\
\hline
\end{tabular}

\subsection{Geo Phone on the Ground}

Amplitude on ground $0.5 \mathrm{~m}$ away from the center of the block was recorded With the same series A, B, $\mathrm{C}, \mathrm{D}$ and $\mathrm{E}$. Another set up of experiment was conducted by placing the geo phones on ground $0.5 \mathrm{~m}$ away from the center of the block and both the parameters frequency and amplitude were recorded 
3.8 Series A $0.5 \mathrm{~m}$ away from the Center of the Block without Isolation Materials

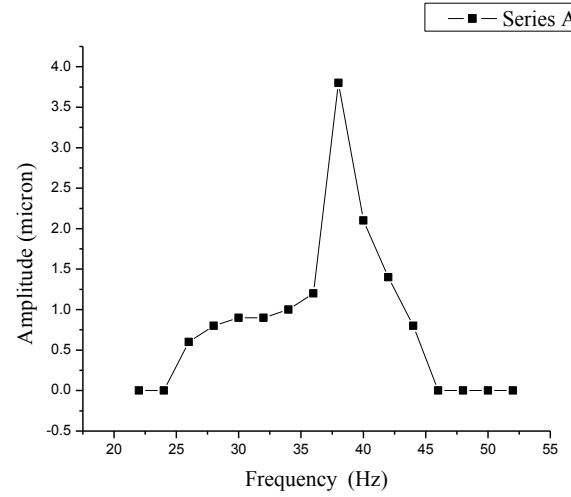

Figure3.7: Variation of frequency to the amplitude for the test series A on ground.

In series a (without isolation) it has been observed that at frequency $38 \mathrm{~Hz}$ the resonance amplitude was gained peak with 3.8 microns which has been observed to be the highest in all the series conducted series $\mathrm{B}, \mathrm{C}, \mathrm{D}, \mathrm{E}$. It can be observed in figure 3.7

\subsection{Series B $0.5 \mathrm{~m}$ away from the Center of the Block with Rubber Pad as Isolation Materials}

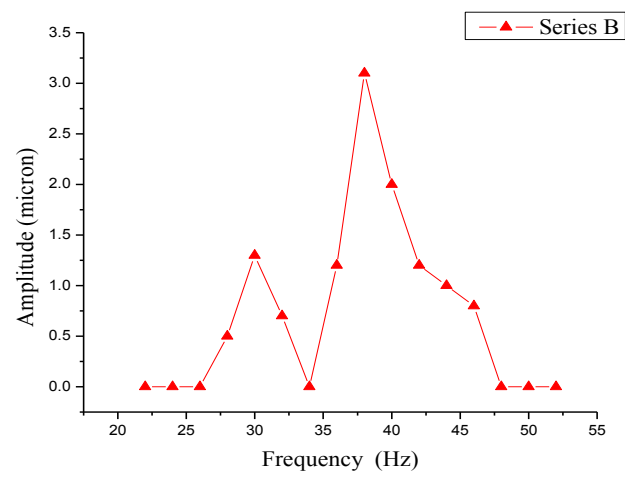

Figure3.8: Variation of frequency to the amplitude for the test series B on ground.

In series B (rubber pad) it has been observed that at frequency $38 \mathrm{~Hz}$ the resonance amplitude was gained peak with 8.1 microns which has been observed to be less than series A but more than series C,D ,E. It can be observed in figure 3.8

3.10Series C $0.5 \mathrm{~m}$ away from the Center of the Block with E P E Foam as Isolation Materials

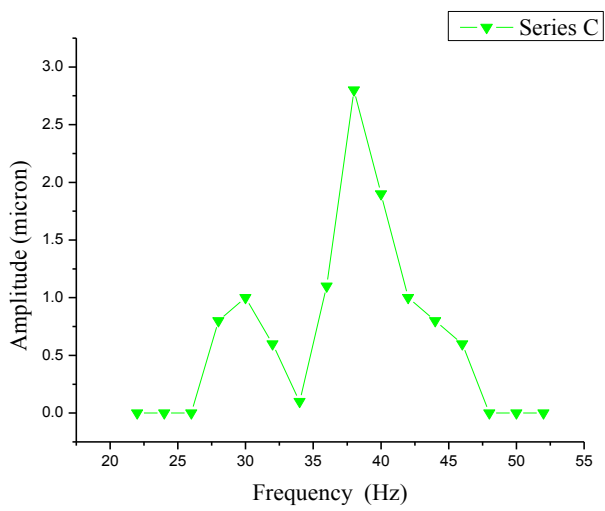

Figure3.9: Variation of frequency to the amplitude for the test series $\mathrm{C}$ on ground. 
In series $\mathrm{C}$ (E P E foam) it has been observed that at frequency $38 \mathrm{~Hz}$ the resonance amplitude was gained peak with 2.8 microns which has been observed to be less than series B but more than series, D, E. It can be observed in figure 3.9

3.11Series D $0.5 \mathrm{~m}$ away from the Center of the Block with sandwich of Rubber Pad and E P E Foam as Isolation Materials

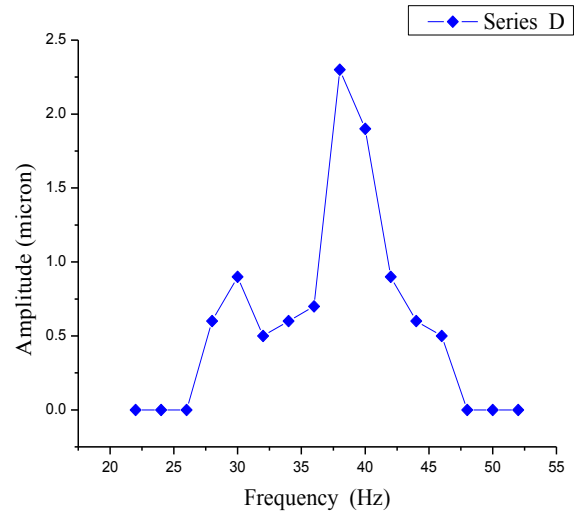

Figure3.10: Variation of frequency to the amplitude for the test for series D on ground.

In series D (rubber pad and E P E foam sandwich) it has been observed that at frequency $38 \mathrm{~Hz}$ the resonance amplitude was gained peak with 6.4 microns which has been observed to be less than series $\mathrm{C}$ but more than series E. It can be observed in figure 3.10

3.12 Series E 0.5 m away from the Center of the Block with sandwich of E P E Foam and Rubber Pad as Isolation Materials

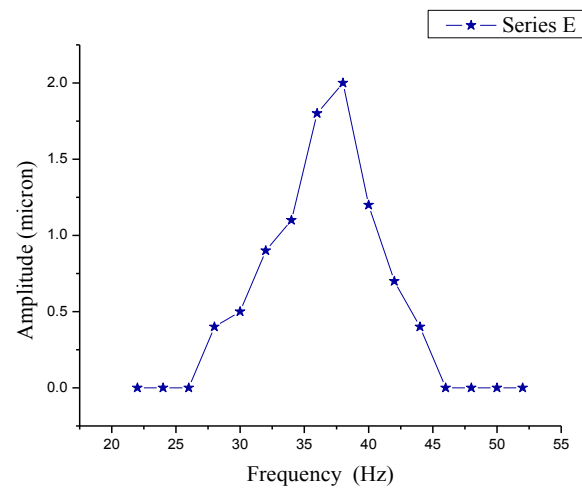

Figure3.11: Variation of frequency to the amplitude for the test series $\mathbf{E}$ on ground.

In series E (sandwich of E P E foam and rubber pad) it has been observed that at frequency $38 \mathrm{~Hz}$ the resonance amplitude was gained peak with 5.8 microns which has been observed to be less than all the series conducted above series A,B ,C,D

Thus it can be concluded that the most vibration absorber is the series E with sandwich of EP E foam and rubber pad in between the oscillator and block even on the ground the resonance is reduced so it can be concluded that for any kind of machine combination of EPE foam and rubber pad can be used to reduce the vibration for the foundation and even to the nearby structures.

\subsection{Comparison of Frequency and Amplitude on Ground}

Even on the ground the comparison of all the series was observed that the isolation material in between the oscillator and the block behaved in reducing the peak resonance of about $53 \%$. It can be seen that even on the ground the most vibration absorber was sandwich of E P E foam with rubber pad in between the oscillator and block. 


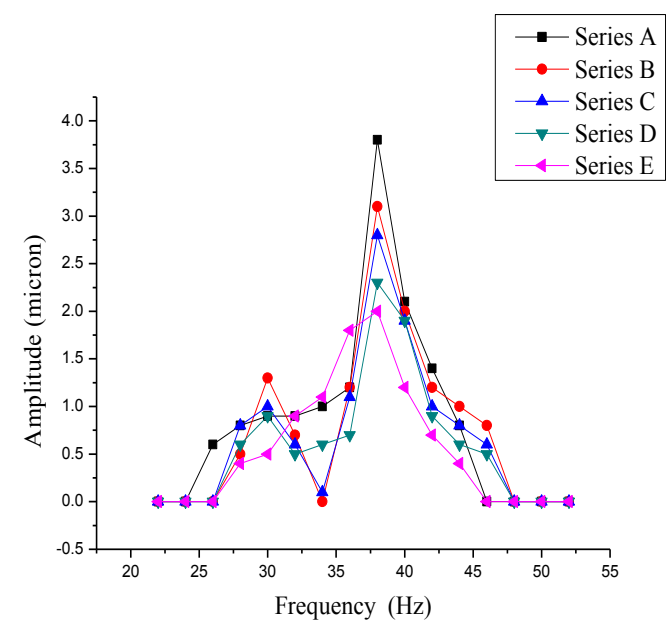

Figure3.12: Variation of frequency to the amplitude for the test series A, B, C, D and E on ground.

Table 3.3: Comparison of Frequency and Amplitude readings taken on Ground for Series A, B, C, D and $\mathbf{E}$

\begin{tabular}{|c|c|c|c|c|c|}
\hline \multirow{2}{*}{$\begin{array}{c}\text { Freq } \\
\text { uen } \\
\text { cy } \\
\text { (Hz) }\end{array}$} & $\begin{array}{c}\text { Without } \\
\text { Isolation } \\
\text { (Series } \\
\text { A) }\end{array}$ & $\begin{array}{c}\text { Rubber } \\
\text { Pad } \\
\text { (Series } \\
\text { B) }\end{array}$ & $\begin{array}{c}\text { Foam } \\
\text { (Series } \\
\text { C) }\end{array}$ & $\begin{array}{c}\text { Rubber } \\
\text { Pad } \\
\text { Foam } \\
\text { (Series } \\
\text { D) }\end{array}$ & $\begin{array}{c}\text { Foam } \\
\text { Rubber Pad } \\
\text { (Series E) }\end{array}$ \\
\hline 20 & 0 & 0 & 0 & 0 & 0 \\
\hline 22 & 0 & 0 & 0 & 0 & 0 \\
\hline 24 & 0.6 & 0 & 0 & 0 & 0 \\
\hline 26 & 0.8 & 0.5 & 0.8 & 0.6 & 0.4 \\
\hline 28 & 0.9 & 1.3 & 1 & 0.9 & 0.5 \\
\hline 30 & 0.9 & 0.7 & 0.6 & 0.5 & 0.9 \\
\hline 32 & 1 & 0 & 0.1 & 0.6 & $\mathbf{1 . 1}$ \\
\hline 34 & 1.2 & 1.2 & 1.1 & 0.7 & 1.8 \\
\hline 36 & 3.8 & 3.1 & 2.8 & 2.3 & 2 \\
\hline 38 & 2.1 & 2 & 1.9 & 1.9 & 1.2 \\
\hline 40 & 1.4 & 1.2 & 1 & 0.9 & 0.7 \\
\hline 42 & 0.8 & 1 & 0.8 & 0.6 & 0.4 \\
\hline 44 & 0 & 0.8 & 0.6 & 0.5 & 0 \\
\hline 46 & 0 & 0 & 0 & 0 & 0 \\
\hline 48 & 0 & 0 & 0 & 0 & 0 \\
\hline 50 & 0 & 0 & 0 & 0 & 0 \\
\hline & & & & & \\
\hline & & & 0.9 & 0.9 \\
\hline
\end{tabular}

Table : Resonant amplitude gained to the frequency for test series A, B, C, D and E

\begin{tabular}{|c|c|c|}
\hline Test & Frequency $(\mathrm{Hz})$ & $\begin{array}{c}\text { Amplitude } \\
\text { (microns) }\end{array}$ \\
\hline Series A & 36 & 3.8 \\
\hline Series B & 36 & 3.1 \\
\hline Series C & 36 & 2.8 \\
\hline Series D & 36 & 2.3 \\
\hline Series E & 36 & 2 \\
\hline
\end{tabular}

\section{Conclusion}

It can be concluded that the most vibration absorber is the series $\mathrm{E}$ with sandwich of $\mathrm{E} \mathrm{P} \mathrm{E}$ foam with rubber pad in between the oscillator and block even on the ground the resonance is reduced so it can be concluded that for any kind of machine combination of E P E foam and rubber pad can be used to reduce the vibration for the foundation and even to reduce damage to the nearby structures.

$>$ It was observed that $45 \%$ of vibration was reduced on block due to the vibration produced by the oscillator

$>$ As the research reduces $45 \%$ of the resonance amplitude with isolated material so it can be used for machines with more vibration in foundation design.

$>$ It is the most economical way of reducing the vibration as compared to open trenches, filled trenches and even increasing the size of the block. 
$>$ On the ground it was observed that the resonance amplitude was reduced to $53 \%$.so it is a very good absorber with a very low cost.

$>$ As springs are corrosive material it loses its properties and durability as time passes where as E P E foam is non corrosive and durable.

\section{Reference}

[1]. Jyant Kumar Vikas Boora "Dynamic Response of a Machine Foundation Combination with Spring Mounting Base and Rubber Pad "Geol Eng (2009) 27:379-389 May 2007 /Accepted: 20 July 2008.

[2]. T.Ozturk and Z.Ozturk "Vibration Absorption and Isolation in Dynamically Loaded Foundations" The $14^{\text {th }}$ World Conference on Earthquake Engineering October 12- 17, 2008, Beijing, China

[3]. Shamsher Prakash Vijay K. Puri "Foundations For Vibrating Machines Special Issue, April-May 2006" of the Journal of Structural Engineering, SERC, Madras. INDIA

[4]. Vijay K. Puri and Braja M. Das "Dynamic Response of Block Foundations" Third International Conference on Case Histories in Geotechnical Engineering, St. Louis, Missouri, June 1-4, 1993, Paper No. 4.08

[5]. P. Anbazhagan T.G. Sitharam, G.L. Sivakumar Babu and Ramul, "Evaluation of dynamic properties of site and Response of Motion Simulator Foundation" Department of Civil Engineering, Indian Institute of Science, Bangalore-

[6]. Ankesh Kumar, Dr. Bappaditya Manna, Prof. K. S. Rao "Effect of Vertical Vibration on Block Foundation Resting on Homogeneous and Layered Medium" International Journal of Engineering Research (ISSN : 2319-6890) Volume No.2, Issue No.7, pp : 452-456

[7]. Ramesh.H., Raghavendra Rao. M.V., Prathap Kumar. M. T. Bhavya.M Nethravathi.S "Dynamic Response of Model Footings Over a Rigid Base Under Vertical Vibrations" The 12th International Conference of International Association for Computer Methods and Advances in Geomechanics (IACMAG) 1-6 October, 2008 Goa, India

[8]. A Boominathan, P C Koteswara Rao, C Sivathanu Pillai And S Hari "Measurement of Dynamic Properties And Evaluation of Liquefaction Potential of A 500mw Prototype Fast Breeder Reactor Site Located In South of India"12 WCEE 2000

[9]. J.E. Luco, J.P. Conte, B. Moaveni, L. Mendoza, and D. Whang "Forced Vibration Tests of the Foundation Block" Third UJNR Workshop on Soil-Structure Interaction, March 29-30, 2004, Menlo Park, California, USA.

[10]. Luna, R. and H. Jadi, "Determination of Dynamic Soil Properties Using Geophysical Methods," Proceedings of the First International Conference on the Application of Geophysical and NDT Methodologies to Transportation Facilities and Infrastructure, St. Louis, MO, December 2000

[11]. R. Cairo, E. Conte and G. Dente "Analysis of pile groups under vertical harmonic vibration" Elsevier Journal of Computers and Geotechnics 32 (2005) 545-554 